\title{
PRE-Screening for Elder Abuse in Sanglah General Hospital, Denpasar, Bali
}

\author{
Shakthy Thewi Pillai
}

\begin{abstract}
Objectives : To identify clinically elderly individuals with elevated risk of being abused based on risk factors and potential forensic markers present.

Methods : The design was a cross-sectional analysis of deidentified data taken from the medical database of Sanglah General Hospital, Denpasar. Participants were individuals aged 60 and above with specific ICD-10 coding indicating potential correlates of abuse reported in Sanglah General Hospital over a 6 year period $(N=898)$. Measured were participant characteristics include demographic characteristics, management and method of payment. The presence of four risk factors and seven potential forensic markers identified using ICD-10 codes were taken and summed. Analytic statistics was used for analysis.

Results : Approximately two-thirds of participants were between ages $60-74,51 \%$ were male, $87 \%$ received out-patient treatment and $85 \%$ used state insurance. $13 \%$ had multiple potential correlates of abuse. Five elders were coded with history of assault, with a further 5 coded for abuse. In logistic regression, four predictors, cognitive impairment, functional dependency, fracture and multiple injuries were identified. However only multiple injuries $(P=0.008)$ was significantly associated with multiple risk factors and potential forensic markers of elder abuse.

Conclusion : Given the ability of forensic markers to identify elder abuse strongly, it is important to further screen elderly patients who present with multiple injuries. More research is needed to further identify forensic markers of elder abuse valid within the Indonesian clinical context.
\end{abstract}

Keywords:- elder abuse; elder mistreatment; neglect; forensic marker

\section{INTRODUCTION}

By 2050, about 25 percent of the population of Indonesia will be older adults. Of this, an estimated 18 percent will be 80 and above.[1] About one to 10 percent of elders have experienced elder abuse.[2] Despite this, only an estimated four percent of cases are charged.[3] Despite this, studies in the field are estimated to be 20 years behind those for domestic violence and child abuse.[4] To date, Indonesia is yet to conduct a national review for the prevalence of nonfatal elder abuse.[5]

Prior studies have identified 13 individual forensic markers linked to elder abuse and neglect. These were signs of malnutrition, signs of dehydration, weight loss, poor hygiene, neglect, psychiatric problems, bruises, abrasion, pressure injuries, lacerations, strangulation, burns, and assault. It was concluded that finding a risk factor of abuse with forensic markers prompts for further investigation.[4]

Another research on community-dwelling elders discovered individual level risks to be psychiatric illness, cognitive impairment, psychological problems, behavioural problems, functional dependency, poor physical health and frailty.[6]

This study is aimed at building on existing research in the field of forensic markers of elder abuse and attempt to prescreen elder abuse and neglect within Sanglah General Hospital, Bali.

\section{MATERIALS AND METHODS}

There were two stages to this research. Firstly, a literature review was conducted to identify common illnesses and injuries linked to elder abuse and neglect. This step accordingly identified risk factors and potential forensic markers of elder abuse and neglect. The second phase involved converting these to International Classification of Disease, Tenth Revision (ICD-10) coding to search the medical databases to investigate the prevalence of elder abuse among adults aged 60 and older within Sanglah General Hospital from January 1, 2013, to December 31, 2018. 898 records were identified.

Participant characteristics measured include demographic characteristics, management and method of payment. The presence of four risk factors; functional dependency, cognitive impairment, frailty, and history of assault, as well as, eight potential forensic markers; malnourishment, pressure injuries, suspect assault, coding for abuse, burns, fractures, and multiple injuries identified using ICD-10 codes were taken and summed.

Descriptive statistics illustrated the frequency of demographic characteristics. A bivariate analysis was done to contrast the characteristics identified multiple correlates of abuse and patients with only single correlates of abuse. Multivariate analysis was conducted by a logistic regression model where a dichotomous variable was the dependent variable which indicated if a patient had more than one correlate of abuse. Demographic characteristics, management, class and method of payment were independent variables in the model.

Revised Manuscript Received on July 18, 2019.

Shakthy Thewi Pillai, Udayana University, Indonesia. (shakthy.pillai@gmail.com) 
Table 1. Forensic Markers of Elder Abuse within the Sample $(N=898)$

\begin{tabular}{lcc}
\hline \multicolumn{1}{c}{$\begin{array}{c}\text { Forensic } \\
\text { Marker }\end{array}$} & ICD-10 Code & n \\
\hline $\begin{array}{l}\text { Functional } \\
\text { Dependency }\end{array}$ & G10-G14, G30-G32, H54.0, & 17 \\
\hline $\begin{array}{l}\text { Cognitive } \\
\text { Impairment }\end{array}$ & F00-F08, F09 & 326 \\
\hline Frailty & Z74.01, Z74.09, Z71.1, & 12 \\
& Z74.2, Z74.3, Z74.8, Z74.9 & \\
\hline $\begin{array}{l}\text { History } \\
\text { Assault }\end{array}$ & Z91.6 & 5 \\
\hline Pressure Injury & L899 & 16 \\
\hline Burn & T31.3, T31.4, T31.5, T31.6, & 2 \\
& T31.7, T31.8, T31.9 & \\
\hline Multiple Injuries & T00-T07 & 4 \\
\hline Malnourishment & Y06, E40-E46 & 60 \\
\hline Coding for Abuse & X85-Y09 & 5 \\
\hline Suspect Assault & Y10-Y34 & 5 \\
\hline Fracture & M84.3 & 522 \\
\hline
\end{tabular}

\section{RESULTS}

Approximately two-thirds of participants were between ages $60-74,51 \%$ were male, $87 \%$ received out-patient treatment and $85 \%$ used state insurance. $13 \%$ had multiple potential correlates of abuse.

Abuse, history of assault and suspect assault each made up less than one percent of the cases identified. The forensic marker most commonly present in the sample were fractures $(\mathrm{n}=522,58.1 \%)$; cognitive impairment $(\mathrm{n}=326,36.3 \%)$; malnourishment $(\mathrm{n}=60,6.7 \%)$; functional dependency $(\mathrm{n}=17,1.9 \%)$; pressure injury $(\mathrm{n}=16,1.8 \%)$; and frailty $(\mathrm{n}=12,1.3 \%)$. The five remaining markers had less than 10 counts each.

Bivariate analyses, as shown in Table 2, indicate that $18.6 \%$ of patients aged 75 or older had multiple correlates of abuse in comparison to $11.6 \%$ of patients between 60 to 74 years old $(\mathrm{P}=0.008)$. Significantly fewer females $(11.2 \%)$ had multiple forensic markers than elder males (15.2\%) $(\mathrm{P}=0.84)$. The presence of multiple markers was almost double among patients hospitalised $(21.2 \%)$ compared to out-patients $(12.1 \%)(\mathrm{P}=0.11)$. Participants who used state medical insurance $(12.3 \%)$ were less likely to have multiple markers than those who used private methods of payment $(19.2 \%)(\mathrm{P}=0.31)$.

Table 2. Sample Characteristics Associated with Multiple Forensic Markers $(\mathbf{N}=\mathbf{8 9 8})$

\begin{tabular}{cccc}
\hline \multirow{2}{*}{ Characteristics } & $\begin{array}{l}\text { Multiple } \\
\text { Forensic } \\
\text { Markers }\end{array}$ & \\
\hline \multirow{2}{*}{ Sex } & Male & $70(15.2 \%)$ & \multirow{2}{*}{.084} \\
\cline { 2 - 3 } & Female & $49(11.2 \%)$ & \\
\hline \multirow{2}{*}{ Age } & $60-74$ & $77(11.6 \%)$ & \multirow{2}{*}{.008} \\
\cline { 2 - 3 } Management & $\geq 75$ & $42(18.6 \%)$ & \\
\cline { 2 - 3 } & Out-patient & $95(12.1 \%)$ & \multirow{2}{*}{.011} \\
\cline { 2 - 3 } & In-patient & $22(21.2 \%)$ & \\
\hline Class & Class III & $95(12.1 \%)$ & .005 \\
\hline
\end{tabular}

\begin{tabular}{|c|c|c|c|}
\hline & $\begin{array}{l}\text { Wing Amerta } \\
\text { Local }\end{array}$ & $22(22.2 \%)$ & \\
\hline \multirow{2}{*}{ Method of Payment } & $\begin{array}{c}\text { State } \\
\text { Insurance }\end{array}$ & $94(12.3 \%)$ & \multirow{2}{*}{.031} \\
\hline & General & $25(19.2 \%)$ & \\
\hline \multirow{2}{*}{$\begin{array}{l}\text { Functional } \\
\text { Dependency }\end{array}$} & Present & $8(47.1 \%)$ & \multirow{2}{*}{.000} \\
\hline & Absent & $111(12.6 \%)$ & \\
\hline \multirow{2}{*}{$\begin{array}{c}\text { Cognitive } \\
\text { Impairment }\end{array}$} & Present & $75(23.0 \%)$ & \multirow{2}{*}{.001} \\
\hline & Absent & $44(7.7 \%)$ & \\
\hline \multirow{2}{*}{ Frailty } & Present & $0(.0 \%)$ & \multirow{2}{*}{.384} \\
\hline & Absent & $119(13.4 \%)$ & \\
\hline \multirow{2}{*}{ Pressure Injury } & Present & $0(.0 \%)$ & \multirow{2}{*}{.150} \\
\hline & Absent & $119(13.5 \%)$ & \\
\hline \multirow{2}{*}{ Burns } & Present & $0(.0 \%)$ & \multirow{2}{*}{1.000} \\
\hline & Absent & $119(13.3 \%)$ & \\
\hline \multirow{2}{*}{ Multiple Injuries } & Present & $2(50.0 \%)$ & \multirow{2}{*}{.087} \\
\hline & Absent & $117(13.1 \%)$ & \\
\hline \multirow{2}{*}{ Malnourishment } & Present & $6(10.0 \%)$ & \multirow{2}{*}{.442} \\
\hline & Absent & $113(13.5 \%)$ & \\
\hline \multirow{2}{*}{ Coding for Abuse } & Present & $2(40.0 \%)$ & \multirow{2}{*}{.133} \\
\hline & Absent & $117(13.1 \%)$ & \\
\hline \multirow{2}{*}{ Suspect Assault } & Present & $2(40.0 \%)$ & \multirow{2}{*}{.133} \\
\hline & Absent & $117(13.1 \%)$ & \\
\hline \multirow{2}{*}{ History of Assault } & Present & $2(40.0 \%)$ & \multirow{2}{*}{.133} \\
\hline & Absent & $117(13.1 \%)$ & \\
\hline \multirow{2}{*}{ Fracture } & Present & $36(6.9 \%)$ & \multirow{2}{*}{.000} \\
\hline & Absent & $83(22.1 \%)$ & \\
\hline
\end{tabular}

Patients with a diagnosis of functional dependency $(47.1 \%)$ were almost four times more likely to have multiple correlates of abuse than those without $(12.6 \%)(\mathrm{P}=0.000)$. Patients with cognitive impairment $(23.0 \%)$ were almost three times more likely to have multiple markers than those without $(7.7 \%)(\mathrm{P}=0.001)$. All patients with frailty, pressure injuries and burns had no other correlate of abuse. Patients coded for multiple injuries $(50.0 \%)$ were more than three times more likely to have multiple forensic markers or risk factors than those without $(13.1 \%)(\mathrm{P}=0.87)$. Patients with malnourishment $(10.0 \%)$ were less likely to have multiple markers than those without $(13.5 \%)(\mathrm{P}=0.442)$. Patients with coding for abuse, suspect assault and history of assault (40.0\%) were each almost three times more likely to have multiple correlates of abuse than those without the coding (13.1\%) $(\mathrm{P}=0.133)$. Patients with fractures (6.9\%) were almost three times less likely to have multiple markers than those without fractures $(22.1 \%)(\mathrm{P}=0.000)$.

Direct logistic regression model of analysis was conducted with multiple forensic markers set as the outcome with 16 factors: age, sex, class, management, method of payment, cognitive impairment, frailty, functional dependency, burns, multiple injuries, malnourishment, abuse, history of assault, pressure injury, suspect assault, and fracture. Using Little's MCAR test deviation from randomness was found to be not statistically significant, $\mathrm{p}=$ .000. A total of 898 cases with missing values were inputted using the EM algorithm through SPSS MVA. 34 cases contained missing values. Upon deletion, 864 individual data were analysed: 
749 with a one forensic marker and 115 with multiple forensic markers. Table 3 results of a direct logistic regression model using variables found to be significant at bivariate analysis. It shows regression coefficients, standard error, P-value and odds ratios for each of the four predictors. significant, $x^{2}(1, N=864)=15.12, p<.005$. Multiple forensic markers of abuse were not significantly associated with age, sex, method of payment, class, management, frailty, pressure injuries, burns, malnourishment, history of assault, suspect assault and coding for abuse. Multiple injuries $(\mathrm{OR}=15.13, \mathrm{SE}=1.017, \mathrm{P}=.008)$ remained significantly associated with markers.

Table 3. Logistic Regression Analysis of Sample Characteristics Associated with Multiple Forensic Markers $(\mathbf{N}=\mathbf{8 6 4})$

\begin{tabular}{lcccc} 
& B & $\begin{array}{c}\text { Standard } \\
\text { Error }\end{array}$ & $\begin{array}{c}\text { P- } \\
\text { Value }\end{array}$ & $\begin{array}{c}\text { Odds } \\
\text { Ratio }\end{array}$ \\
\hline $\begin{array}{l}\text { Functional } \\
\text { Dependency }\end{array}$ & 21.491 & $7.736 \mathrm{E} 3$ & .998 & $2.155 \mathrm{E} 9$ \\
\hline $\begin{array}{l}\text { Cognitive } \\
\text { Impairment }\end{array}$ & 20.006 & $7.736 \mathrm{E} 3$ & .998 & $4.882 \mathrm{E} 8$ \\
\hline $\begin{array}{l}\text { Multiple } \\
\text { Injuries }\end{array}$ & 2.717 & 1.017 & .008 & 15.129 \\
\hline Fracture & 18.487 & $7.736 \mathrm{E} 3$ & .998 & $1.068 \mathrm{E} 8$ \\
\hline
\end{tabular}

\section{DISCUSSION}

Elder adults are a more vulnerable population due to pathologic changes as well as aging related illnesses. It is often difficult to differentiate evidence of elder abuse and accidents that are side effects of drugs of apart of the aging sequelae.[7] Hence, pattern of injuries need to be analysed to identify indicators of elder abuse and neglect.

These findings showed that elderly patients with multiple correlates of abuse were more likely to be hospitalised. This is in accordance to available research which links elder abuse to elevated emergency department use.[4]

In contrast, cognitive impairment functional dependency and frailty were not found to be significant statistically. Female sex, over 75 years of age and past abuse were also statistically insignificant in our study. Payment method which was used as an indicator of socioeconomic standing was also not linked significantly to elder abuse in the studied population. This despite a systematic review finding them to be risk factors.[6]

Six markers; signs of malnutrition, multiple injuries, assault, burns, fractures and pressure injuries were tested using direct logistic regression. Out of which, the only Out of the four, only multiple injuries was statistically

statistically significant marker was multiple injuries. This is contrary to the literature review which found all related with elder abuse.[4] Contrary results are possibly caused by difference in population characteristics, with varied socioeconomy, culture and elder protections in force.

Eight forensic markers were identified during literature review; signs of dehydration, psychiatric illness, weight loss, poor hygiene, bruising, strangulation, abrasion and laceration were not regularly coded for in the medical database of Sanglah General Hospital. Future research using larger population samples is needed to better analyse the risk factors and forensic markers identified to pre-screen for elder abuse.

This study uses de-identified patient data to identify potential cases of abuse and neglect. This allows comparisons to be made between states and countries while maintaining anonymity. However, the de-identified information lead to further investigation of the medical records being inaccessible. Moreover, the use of ICD-10 coding is affected by variance in clinical coding procedure within the hospital studied. This may lead to underreporting of risk factors and forensic markers. Further research in multiple hospitals should be conducted for greater accuracy.

\section{CONCLUSIONS}

To our knowledge, this is the first study in Indonesia that uses ICD coding in an attempt to pre-screen for non-fatal abuse and neglect of elders. The use of literature review to improve specificity of screening. In summary, elder abuse is both common- affecting one to 10 percent of elders, as well as detectable by certain forensic markers. Medical professionals need to be aware of these so as to better determine individuals at high risk of abuse.

In view of that certain forensic markers can be used to identify possible cases of elder abuse, it is essential to keep pre-screening older individuals when the forensic marker, multiple injuries is present. More research is needed to support both this study as well as the literature on elder abuse. This helps in the development of evidence-based screening tool for more effective detection of elder abuse.

\section{REFERENCES}

1. United Nations. Population Ageing and Development 2012. New York: United Nations; 2012.

2. World Health Organization. Elder Abuse. [Internet]; 2016 [Accessed 21 Jul. 2016] Available from:

http://www.who.int/ageing/projects/elder_abuse/en/

3. Departemen Kesehatan. 2013. Indeks Pembangunan Kesehatan Masyarakat. Jakarta: Badan Litbangkes, Depkes RI, 2013

4. Gironda, M., Nguyen, A. and Mosqueda, L.. Is This Broken Bone

Because of Abuse? Characteristics and Comorbid Diagnoses 
in Older Adults with Fractures. Journal of the American Geriatrics Society; 2016.

5. Organization, W.. Global Status Report on Violence Prevention. Geneva: World Health Organization; 2014. p.51

6. Johannesen, M. and LoGiudice, D.. Elder Abuse: A Systematic Review of Risk Factors in CommunityDwelling Elders. Age And Ageing; 2013. 42(3), pp.292-298.

7. Gibbs, L.. Understanding the Medical Markers of Elder Abuse and Neglect. Clinics in Geriatric Medicine; 2014. 30(4), pp.687-712. 